\title{
A experiência de cuidar da mulher alcoolista na família*
}

\author{
THE EXPERIENCE OF CARING FOR AN ALCOHOLIC WOMAN IN THE FAMILY
}

LA EXPERIENCIA DE CUIDAR DE LA MUJER ALCOHÓLICA EN LA FAMILIA

\author{
Alessandro Marques dos Santos ${ }^{1}$, Mara Regina Santos da Silva²
}

\section{RESUMO}

Este estudo tem como objetivo investigar as práticas de cuidados desenvolvidas pela família à mulher alcoolista e conhecer a percepção desta em relação aos cuidados que recebe. Trata-se de um estudo de caso, desenvolvido com uma abordagem qualitativa, cujos dados foram coletados através de entrevistas semi-estruturadas, realizadas em 2008, no domicílio de uma família de classe média, residente em um município no extremo sul do Brasil e, posteriormente, submetidos à análise de conteúdo. Os resultados mostram que os cuidados desenvolvidos pela família são centrados nas necessidades de alimentação, higiene, sono, repouso, encaminhamento aos serviços especializados para a desintoxicação e que a mulher alcoolista interpreta esses esforços como sendo ações de controle sobre sua vida e punição pela sua condição de dependência. Destaca-se que a maneira da família cuidar modifica-se no mesmo compasso em que o alcoolismo evolui.

\section{DESCRITORES}

Mulheres

Alcoolismo

Família

Cuidados de enfermagem

\section{ABSTRACT}

This study aims at investigating the care practices developed by the family of an alcoholic woman and understanding her perception of the care she is receiving. It is a case study, developed using a qualitative approach. Data were collected through semi-structured interviews, performed in 2008 in a middle-class family home in a town in southern Brazil. The data were later submitted to analysis. The results show that the care provided by the family is centered on the needs for food, hygiene, sleep, rest and the transporting of the woman to specialized detoxification services, and that the woman views these actions as a form of control and punishment due to her addiction. We highlight the way the family cares for the woman and how this changed as her alcoholism evolved.

DESCRIPTORS
Women
Alcoholism
Family
Nursing care

\section{RESUMEN}

Este estudio objetiva investigar las prácticas de cuidados desarrollados por las familia a la mujer alcohólica y conocer la percepción de ésta en relación a los cuidados que recibe. Estudio de caso, desarrollado con abordaje cualitativo, cuyos datos fueron recolectados a través de entrevistas semiestructuradas, realizadas en 2008 , en el domicilio de una familia de clase media, residente en un municipio del extremo sur de Brasil y, posteriormente, sometidos a análisis de contenidos. Los resultados muestran que los cuidados desarrollados por la familia se centran en las necesidades de alimentación, higiene, sueño, reposo, derivación a los servicios especializados en desintoxicación, y que la mujer alcohólica los percibe como acciones de control sobre su vida y castigos por su condición de dependencia. Se pone en destaque que el modo de cuidar de la familia se modifica en la misma medida en que el alcoholismo evoluciona.

\section{DESCRIPTORES}

Mujeres

Alcoholismo

Familia

Atención en enfermería 


\section{INTRODUÇÃO}

O alcoolismo é um dos principais problemas de saúde pública no Brasil. Suas repercussões estão associadas aos altos índices de mortes no trânsito, absenteísmo no trabalho, desentendimentos familiares, separação de casais e complicações na saúde não apenas da pessoa que bebe, mas, também, daquelas que com ela convivem principalmente seus familiares. É um problema que atinge indiscriminadamente homens, mulheres de todas as idades, inclusive crianças, de todas as classes sociais ${ }^{(1)}$ e cuja prevenção é dificultada pelo fato das bebidas alcoólicas serem vendidas livremente com frágeis alertas à população quanto aos seus malefícios para a saúde.

Embora os índices oficiais apontem a predominância do alcoolismo entre os homens ${ }^{(2)}$, é alta a prevalência entre as mulheres o que exige atenção uma vez que as repercussões na saúde destas são, habitualmente, mais intensas, pois mais cedo do que os homens as degenerações fisiológicas são evidenciadas. Dentre essas, os distúrbios da função sexual, como dismenorréia, hipermenorréia e desconforto pré-menstrual, variações no ciclo menstrual e maior ocorrência de cirurgias ginecológicas $^{(3)}$. Ao mesmo tempo, é importante observar que a mulher procura clínicas e serviços de saúde para consultas ginecológicas ou para cuidar, por exemplo, de sintomas depressivos, mas, nestas ocasiões, frequentemente, omite sua condição de dependente do álcool. Esse fato evidencia os tabus em relação à mulher alcoolista, tanto no âmbito familiar, quanto na sociedade em geral ${ }^{(4)}$.

Do ponto de vista social observa-se, ainda, a persistência de censura moral que condena com mais rigor certos comportamentos femininos, incluindo o uso abusivo de bebida alcoólica. Provavelmente, em função destes preconceitos a mulher acaba sendo marginalizada e perde sua credibilidade, visto que a condição de alcoolista interfere no desempenho dos papéis que social e culturalmente lhe são atribuídos, ou seja, de educar, orientar e proteger os filhos e a família(5).

Particularmente, no âmbito da família, as repercussões negativas do alcoolismo feminino se mostram mais fortemente. Na maioria dos casos, a família mantém a esperança de que a pessoa um dia irá parar de beber, mas, quando isso não acontece, podem ocorrer rupturas das relações intra familiares, sendo comum a expressão de sentimentos ambivalentes, os quais oscilam entre o sofrimento e a esperança, o amor e o ódio, a satisfação e a insatisfação(6). Além disso, o adoecer em decorrência do alcoolismo não fica restrito à pessoa dependente, pois de alguma maneira atinge todos os membros da família. Frequentemente, a relação de confiança entre a mulher os filhos e o esposo fica profundamente prejudicada e a mãe-esposa gradativamente perde o respeito e a credibilidade diante de sua família.

Quando se trata de alcoolismo feminino é necessário, portanto, ficar atento não apenas aos problemas clínicos, mas também, as repercussões diretas que essa doença provoca nos papéis que a mulher desempenha no meio familiar. Na sociedade contemporânea ainda é atribuída à mulher maiores responsabilidades no contexto familiar ${ }^{(3)}$ e quando outras pessoas precisam assumir essas funções, geralmente, emergem os conflitos familiares, pois aquela que deveria ser a cuidadora encontra-se impossibilitada, devido ao alcoolismo. Nesse contexto, a mulher passa a ser estigmatizada pela família que, em geral, tem dificuldades para aceitar e compreender o alcoolismo como doença e, consequentemente não a reconhece como uma pessoa que necessita ser cuidada.

No âmbito da literatura observa-se uma lacuna em relação às implicações importantes relacionadas com a questão do alcoolismo feminino. A ênfase maior é dirigida para as repercussões sociais, epidemiológicas e os aspectos clínicos e psíquicos do alcoolismo $^{(7-9)}$. De modo geral, os estudos não contemplam, na mesma proporção, a mulher alcoolista e nem mesmo as práticas de cuidado desenvolvidas pela família. Tal situação acontece, também, nas revistas de acesso popular, cujos temas estão geralmente centrados nos distúrbios clínicos, sociais, psíquicos manifestados pelo homem alcoolista, raramente fazendo referência ao alcoolismo feminino e suas complicações.

Na grande maioria dos estudos, a muIher nem mesmo é citada, ficando o alcoolismo associado preponderantemente ao homem. Nessas condições, comprova-se a necessidade de aprofundar o estudo acerca do alcoolismo feminino, mais especificamente em relação às maneiras de cuidar da mulher alcoolista, no contexto da família, uma vez que os conflitos entre seus membros, em geral, são significativos e se repercutem particularmente sobre as relações de afeto, de cuidado e de proteção entre eles ${ }^{(4,6,10)}$.

\section{OBJETIVOS}

Com base nas considerações apresentadas, dois objetivos são contemplados neste estudo. O primeiro está voltado para a investigação das práticas de cuidado à mulher alcoolista desenvolvidas pela família e o segundo direcionado para conhecer a percepção desta mulher acerca dos cuidados que recebe no âmbito de sua família. 


\section{MÉTODO}

Estudo de caso de natureza qualitativa, desenvolvido com uma família constituída de cinco pessoas: a mulher alcoolista (M1) de cinquenta e um anos; sua mãe (F1) a principal cuidadora, com oitenta anos; a fiIha de M1 com vinte anos; seu marido e o filho deste casal, um menino de cinco anos. A mulher alcoolista iniciou a beber aos dezesseis anos e sua história familiar mostra a existência de dois tios, irmãos de sua mãe, que também bebiam e foram cuidados por F1, desde a infância até que na idade adulta foram a óbito em consequência do uso abusivo de álcool.

A família tem boas condições sociais e econômicas, a casa onde moram é ampla e confortável, situada em um bairro de classe média, em uma cidade do extremo sul do país. M1 aparenta mais idade do que realmente tem, em geral mostra-se hostil, irônica e agressiva com os familiares o que evidencia relações familiares conflituosas. A família frequenta um Centro de Atenção Psicossocial (CAPS), M1 para o tratamento e os demais familiares para as reuniões de grupo de familiar. Esse CAPS é especializado no tratamento e cuidado de pessoas com dependência química em álcool e drogas.

Os dados foram coletados entre agosto a setembro de 2008, através de entrevistas semi-estruturadas, com perguntas abertas e fechadas, as quais foram gravadas e, posteriormente transcritas, conforme um roteiro elaborado para este fim. As entrevistas foram realizadas na residência da família, sendo que dois encontros foram agendados, um para entrevistar a muIher alcoolista e o outro com a familiar cuidadora. A entrevista com M1 durou em torno de uma hora e com a mãe cuidadora em torno de duas horas.

Os dados foram submetidos à análise de conteúdo ${ }^{(11)}$ seguindo os passos de pré-análise, a partir de leitura flutuante de forma exaustiva para obter uma visão do conjunto dos dados e apreender suas particularidades. Buscou-se expressões significativas que identificavam o cuidado desenvolvido pela família e percebido pela mulher alcoolista. Após, foi realizado a interpretação dos resultados contemplando a discussão destes e permitindo a interação do objetivo do estudo com questões e pressupostos embasados nos conceitos teóricos que fundamentam a pesquisa.

O estudo recebeu uma certificação ética de um Comitê de Ética em Pesquisa, sob o registro no. 2008/9. De acordo com a Resolução 196/96 do Ministério da Saúde, para pesquisas envolvendo seres humanos, foi garantido o sigilo e anonimato dos participantes, assim como o direito de acesso aos dados e de desistência de sua participação a qualquer momento. Todos os membros da família assinaram o Termo de Consentimento Livre e Esclarecido.

\section{RESULTADOS}

\section{As práticas de cuidados desenvolvidas pela família}

O envolvimento de M1 com o alcoolismo iniciou na adolescência, por volta dos dezesseis anos, quando fugia da escola juntamente com outras colegas, para beberem cerveja em um bar próximo. Nesta época, a forma da mãe cuidar era, predominantemente, através do monitoramento das atitudes e do comportamento da filha adolescente. Especificamente com a ingesta de álcool a mãe refere que não se preocupava, estava atenta apenas com o desempenho escolar da filha, pois acreditava que o uso de bebida alcoólica era uma maneira de a adolescente chamar atenção.

A mãe (F1) começou a se preocupar, de fato, com a ingesta de álcool da filha quando esta chegou à idade adulta. Neste período, M1 então com vinte e cinco anos, bebia de forma imoderada durante toda a semana, acentuando-se o desinteresse gradativo pela própria aparência pessoal. Mesmo assim, F2 não reconhecia (ou não admitia) o alcoolismo da filha, o que é bastante comum entre familiares de pessoas alcoolistas, que geralmente negam a dependência para não enfrentar as repercussões negativas do alcoolismo.

Nesta etapa do ciclo vital, a dependência de M1 já se constituía em uma situação de exposição pública para a família, provocadora de mal estar, pois representava uma violação dos valores predominantes. Especialmente porque para esta família o alcoolismo é considerado como prática exclusiva do homem como se observa através da fala de F1:

Eu escondi no começo porque ela tinha muitas amizades, pessoas da alta sociedade. Eu tinha vergonha que as vizinhas soubessem que minha filha era alcoólatra. Era uma vergonha tremenda, porque uma mulher beber é pior que um homem beber (F1).

Aos trinta e cinco anos M1 casou-se e foi morar distante de sua família. Neste período estava cursando o ensino superior e continuava bebendo, mesmo durante o período em que estava grávida de sua única filha. A mãe (F1) era presença constante, visitando-a seguidamente, ocasião em que constatava as reclamações do genro de que a esposa descuidava do lar e negligenciava os cuidados de si mesma e da filha. M1 bebia diariamente, grandes quantidades e se tornou habitual o marido chegar em casa e encontrá-la embriagada. Em consequência disso, ele assumia sozinho o cuidado com o lar e com a menina recém nascida. Dessa forma, o casamento não durou muito e M1 retornou para sua família de origem, trazendo consigo a filha pequena.

A partir deste retorno, com a convivência, a confiança entre F1 e M1 se tornou frágil e os laços afetivos foram se rompendo em decorrência dos inúmeros problemas 
vivenciados pela família com a dependência de M1. Frequentemente F1 precisava resgatar a filha embriagada da rua e colocá-la no quarto para dormir. Nesta época, esta era a maneira predominante de F1 cuidar de M1.

A partir deste período os cuidados desenvolvidos por F1 se constituíam em permanecer em vigília durante todas as noites em que sua filha saía para se divertir, pois acreditava ser necessário preservá-la do descontentamento do pai caso este a encontrasse embriagada, já que ele não aceitava dependência alcoólica de M1. Segundo F1 ela precisava, também, preservar a neta, evitando que a menina visse a mãe embriagada, pois era ainda muito pequena para entender a situação. Evidencia-se ao longo da entrevista com F1 que esta procurava ocultar dos demais membros da família as situações difíceis desencadeadas pelo alcoolismo da filha, como a condição de embriaguês, as palavras pejorativas que $\mathrm{M} 1$ lhe dirigia e o estado físico deplorável que M1 costumava chegar em casa. De acordo com seu ponto de vista, essa era a maneira de cuidar não só de sua filha, mas de sua família. A fala seguinte ilustra esta situação.

Eu não deixava a filha dela ver porque era pequena, eu não deixava o meu marido ver porque ele estava doente. Eu ficava a noite sentada controlando. Sabe como é mãe: abafa (F1).

Ao mesmo tempo em que F1 cuidava da filha alcoolista e dos demais membros da família, não escondia a sobrecarga social e emocional de conviver com o alcoolismo de M1 e o sentimento de vergonha que sentia em relação às outras pessoas. Este sentimento parecia relacionado com os valores que imperavam nesta família, os quais conflitavam com o fato de ser uma mulher, conforme evidencia o relato abaixo:

Eu tinha vergonha das minhas amigas, se elas ficassem sabendo, porque a gente tinha uma vida muito social, eu tentava de tudo para que ninguém viesse aqui [em casa] (F1).

$\mathrm{O}$ alcoolismo de M1 intensificou desde a morte do pai, com quem tinha uma boa relação de companheirismo principalmente nos momentos mais difíceis. A partir desse evento $M 1$ passou a ingerir outras substâncias que continham álcool como perfume, gasolina e desinfetantes. Em virtude disso, F1, já com idade avançada, setenta e cinco anos, e apresentando dificuldades para executar os cuidados à filha alcoolista, pediu ajuda à neta, que, nessa época, já casada, morava com o marido e um filho pequeno. Assim, a filha de $\mathrm{M} 1$ passou a residir com elas e a dividir os cuidados da mãe, especialmente aqueles relacionados com o controle das saídas de M1 de casa e o manuseio do dinheiro. Isto contribui para intensificar os conflitos familiares já que M1 considerava essas práticas punitivas e controladoras.

Entretanto, mesmo em meio às relações de afeto perturbadas, F1 sempre prestou os cuidados relacionados com as necessidades básicas. Esses cuidados incluiam dar banho, trocar as roupas, alimentar e depois a colocar para dormir, especialmente quando M1 chegava em casa alcoolizada. Apesar disso, M1 diz que não lembra ter recebido esses cuidados.

Evidencia-se uma família convivendo diariamente com conflitos, situações desajustadas, cansada pelas inúmeras discussões e desentendimentos e sem esperança na recuperação de M1. Reflexo disso são os sentimentos ambivalentes experimentados: ao mesmo tempo em que F1 cuida e protege M1 das recaídas e a assiste com os cuidados básicos, experimenta a insatisfação e o sofrimento que a dependência da filha trás à família, como retrata a fala seguinte:

Na última vez, ela não conseguiu abrir a porta e caiu. Eu a puxei para dentro (...) senti vontade de matá-la, me ajoelhei e pedi a Deus que me ajudasse. Peguei o travesseiro, coloquei debaixo da cabeça dela, e tive vontade de abafála. Pensei: vou matar porque não aguento mais, eu não tenho mais vida. Pedi a Deus que me orientasse naquela hora. Deixe, mas a minha vontade foi fazer isso (F1).

O estado de embriaguês de M1 se tornou uma rotina e a ajuda apenas da neta já não era suficiente para controlar a situação. Elas buscam, então, o auxílio de outros familiares e com isso conseguem por mais algum tempo cuidar de M1 no seio da família. Entretanto, a condição clínica e emocional evolui e, em seguida, é necessário recorrer aos serviços especializados, como hospitais psiquiátricos e clínicas para reabilitação de dependentes químicos.

Destacam-se novamente os sentimentos ambivalentes de $\mathrm{F} 1$ em relação a $\mathrm{M} 1$. Ao mesmo tempo em que flui o desejo de matar a fim de terminar com o sofrimento da família e da filha, F1 busca ajuda nos demais familiares para socorrer a filha o que denota os sentimentos de solidariedade e de afeto, que vão de encontro ao desejo de matar, ou seja, o papel de mãe como protetora e cuidadora impera neste momento.

A dependência de $M 1$, segregada no seio da família, foi gradativamente sendo exposta às outras pessoas do convívio social da família, inclusive a vizinhança. Para F1, à medida que o tempo passava já não importava mais manter este segredo, porque a esperança de recuperação e de cura de M1 gradativamente foi sendo perdida. Da mesma forma, a motivação de F1 estava fragilizada, pois fisicamente não tinha mais energia para suportar a dependência de $M 1$, já não se importava com a exposição de seu cotidiano familiar e aceitava sem resistência a ajuda de outras pessoas para cuidar de M1.

\section{Um dia ela caiu por ai e umas pessoas a colocaram para dentro de casa, ela disse que morava aqui e deu o nú- mero da casa... Eles a trouxeram de carro até aqui, por- que estava totalmente embriagada, não conseguia nem caminhar (F1).}

Quando esgota a capacidade de cuidar, a família busca apoio na rede social que neste estudo está representada pelos vizinhos, os parentes e os serviços comunitários, 
incluindo os hospitais psiquiátricos, o serviço de pronto atendimento, as urgências e emergências dos hospitais gerais. As falas que seguem remetem a isso:

Eu chamava os bombeiros, eu chamava a assistência, e eles diziam: está alcoolizada. (...) depois ela foi para o sanatório, já esteve internada lá cinco vezes (...). Agora ela está no CAPS, até que estou achando que está bem... ela está se arrependendo de tudo que fez... Nós não precisávamos estar se preocupando com essas coisas (F1).

\section{A percepção da mulher alcoolista acerca dos cuidados que Ihes foram prestados}

Quando iniciou sua participação neste estudo fazia dois meses que M1 estava em abstinência. Foram trinta e quatro anos de alcoolismo avaliados por ela própria como um período de grandes perdas, tanto familiares como individuais. $O$ isolamento em relação à sua família foi a perda que the parece mais significativa. A falência das relações familiares e as desconfianças da família são ainda notáveis e M1 reconhece que o convívio está desgastado pelos inúmeros problemas que vivenciaram, mas reivindica uma oportunidade de reconstruir as relações familiares:

Eu acredito que elas passaram momentos ruins, que sofreram a maneira delas, mas precisam analisar as minhas atitudes e constatar que no dia a dia estou mudando, lutando, para melhorar, e não ficar vinte e quatro horas atirando em cara, porque ao invés de ajudar enterra mais (...) é difícil esquecer (M1).

Apesar das práticas de cuidados realizadas principalmente por sua mãe e sua filha, ao longo da evolução do alcoolismo, M1 refere que eram focadas apenas na sua relação com o álcool. Não eram cuidados dirigidos à sua pessoa e sim cuidados punitivos e de policiamento que incluíam não sair de casa, não manusear dinheiro e ser inquirida se havia bebido quando retornava da rua.

Elas me cuidavam no sentido de me controlar, quando eu saia e quando voltava, observavam como eu chegava (...) muitas vezes estou no meu quarto e minha filha invade, acho que é para ver se não estou bebendo. Minha filha comanda tudo até hoje, o dinheiro é ela quem comanda. Então eu acho que neste sentido não é cuidado, pelo menos comigo não (M1).

M1 percebe os cuidados desenvolvidos pelos familiares como controladores e não como ações necessárias para preservar sua saúde, em uma etapa de sua vida em que a dependência já repercutia em problemas sociais, emocionais e clínicos. Para a família era preciso estabelecer limites ao comportamento de $M 1$, mas não havia convergência entre a finalidade e a percepção do cuidado. Assim, a família foi perdendo a esperança de que a abstinência acontecesse e a fragilização dos laços afetivos foi inevitável, abrindo espaço para os conflitos entre seus membros e a culpabilização pela condição em que se encontram.
De modo geral pode-se dizer que M1 não se reconhece cuidada pelos seus familiares, porque esses não lhes dispensam carinho, amor e atenção. Do seu ponto de vista, cuidado está relacionado com afeto, atenção e estes ela não encontra em sua família. Assim, a preocupação e o envolvimento de F1 durante toda a evolução do alcoolismo não são reconhecidas por M1, embora sua mãe e sua filha tenham expressado esse compromisso de ajudar e apoiar. Constata-se novamente um descompasso entre as práticas de cuidado desenvolvidas por F1 e o que M1 percebe como sendo cuidado.

Carinho, atenção, ser considerada como um ser humano, como normal, deixarem de lado o que eu fui e o que ainda sou: uma alcoólatra em recuperação (...) me considerarem um ser humano normal, dar um crédito de confiança, me dar aquele carinho (M1).

Apenas na relação com o pai M1 sentia-se cuidada de forma carinhosa, afetiva e com dedicação. Entretanto, apesar desta relação ser percebida de forma harmoniosa, os episódios de embriaguês eram comuns a ambos, pai e filha bebiam juntos. A mãe condenava esses comportamentos, relacionando-os com uma liberdade demasiada e que poderia vir a prejudicar a filha. Desempenhava a função de alertar e, muitas vezes, de coibir estas práticas, mas não era ouvida nem pelo esposo, nem pela filha.

Senti muita falta do meu pai, era muito meu amigo, meu companheiro, me colocava para cima, me elogiava. Eu sentava no colo dele e eu chorava, conversava. O meu pai graças a Deus não chegou a ver meu estado de alcoolista, bebia comigo, mas bebíamos socialmente, tomava uns porrezinhos de vez em quando nós dois (M1).

Outra prática de cuidado percebida por M1 foi a busca de serviços especializados, acionados apenas quando a família perdeu a esperança de que ela chegasse à abstinência. M1 acredita que não teria sobrevivido ao alcoolismo se isso não tivesse acontecido, pois, segundo suas próprias palavras, ela chegou ao descontrole total e não sabia como chegava a casa, porque se esquecia dos acontecimentos, sentia um tipo de apagão e quando acordava já estava em casa, ou em alguma instituição de saúde.

Nestas ocasiões, os cuidados percebidos por M1 eram apenas aqueles desenvolvidos pelos profissionais da saúde. Reconhecia na decisão da família buscar ajuda nos serviços de saúde uma forma de punição e não de cuidado para com a sua pessoa, mesmo os familiares acompanhando-a de perto durante os períodos de desintoxicações a que fora submetida. Os relatos de M1 são variados em relação às internações (em torno de seis) e durante as entrevistas procurava demonstrar despreocupação sugerindo que tentava não se abater pela decisão dos familiares de interná-la.

Nesta última internação eu pensei muito, estava destruindo a minha vida, por coisas que não valiam a pena, que não iam levar a nada, não iam comovê-las e quem estava se destruindo com isso era eu. Enfim. eu tinha chegado ao meu limite (M1). 
A fala de M1 faz a demarcação do momento a partir do qual começa a reconhecer em si um desejo de mudar sua condição, pois, entende que quando se está bebendo não se têm problemas, se resolve tudo, mas depois as consequências são grandes, a pessoa fica desacreditada, desrespeitada e desconsiderada (M1). Percebe o prejuízo para si mesma, a falência das relações familiares, mas não reconhece sua família como forma de apoio para o enfrentamento da dependência. Entretanto, deseja provar para os familiares que conseguirá manter-se sóbria e como foi referido anteriormente reivindica uma oportunidade de reconstruir as relações familiares. Assim, M1 iniciou uma busca pela abstinência e quando este estudo encerrou completava dois meses sem ingerir bebidas alcoólicas.

\section{DISCUSSÃO}

Os resultados deste estudo mostram que a forma da família cuidar foi modificando na medida em que o alcoolismo de M1 se instalava, ou seja, no mesmo compasso evoluíam o processo de adoecer e o processo de cuidar. Nas fases iniciais predominavam as práticas de monitoramento do comportamento e aproveitamento da filha na escola, o abuso de bebidas alcoólicas era considerado pelos pais como próprio da adolescência. No entanto, era o começo de uma trajetória de dependência alcoólica que não foi identificada e, consequentemente, não foi prevenida. Com isso, esse estudo confirma a literatura que ressalta ser a passagem do beber social para o alcoolismo um processo que pode levar muitos anos, demarcado por uma longa interface entre o beber normal e a dependência, durante o qual a ingesta de álcool assume prioridade em relação as outras atividades ${ }^{(12)}$.

Da mesma forma, os valores, as crenças, os costumes e os preconceitos predominantes na família, os quais vinculam o alcoolismo a uma prática masculina, um vício e não uma doença contribuiu para que não fosse identificado o potencial de risco que o comportamento de M1 representava. São valores que impregnam as relações familiares e se transmitem através das gerações ${ }^{(13)}$. No caso desta família em estudo, evidencia-se essa transmissão através das dificuldades e conflitos vivenciados anos mais tarde, especialmente entre $\mathrm{M} 1 \mathrm{e}$ sua filha e nas tentativas de F1 esconder a dependência de M1, através do isolamento social da família.

Essa mesma postura pode ser observada na sociedade de um modo geral e, particularmente entre alguns profissionais da saúde que referem dificuldades para cuidar de pessoas alcoolistas e associam com os valores e as crenças da própria família ${ }^{(10)}$. Possivelmente movidos por esses valores consideram a mulher alcoolista como imoral e seu comportamento como inadequado, aumentando cada vez mais o sofrimento e o estigma social em relação a essas pessoas ${ }^{(10)}$.

A presença constante de F1 e o apoio para que M1 não fracasse em seu papel de mãe e esposa são práticas de cuidado que se intensificam quando a família reconhece que não é mais possível negar o alcoolismo. Da mesma forma, intensificam-se os sentimentos de indignação, vergonha e os conflitos na medida em que M1 negligencia sua própria higiene pessoal e, então, a família reconhece o alcoolismo instalado em uma mulher adulta que depende de outra para a manutenção de suas necessidades básicas. Este estágio em que se encontra M1 confirma que após o advento do alcoolismo, a dinâmica familiar muda e o risco de que mulher alcoolista seja abandonada pelos membros da família é elevado(5).

Diversos autores referem que os sentimentos de vergonha em relação à pessoa alcoolista surgem devido às situações constrangedoras que ela provoca para a família(4-6-14). Quando instalada a dependência a pessoa perde o senso crítico em relação à vida social, descuida de suas necessidades mais elementares e surgem transtornos físicos e psíquicos. Nessas condições, a família habitualmente se mantém em estado de alerta constante, o que pode provocar desgastes emocionais, físicos, angústia, insegurança e desânimo em relação à recuperação de uma condição de vida melhor. Em síntese, o diálogo entre seus membros torna-se difícil e gradativamente a família vai perdendo a esperança de imputar qualidade ao convívio social(12-15).

As práticas de cuidado evidenciadas neste estudo confirmam a finalidade dos cuidados familiares apontada por outros autores incluindo a intenção proporcionar bem-estar, saúde e o desenvolvimento de seus membros ${ }^{(16)}$. Da mesma forma, evidenciam que a família garante a proteção de seus membros com medidas relacionadas a segurança física, emocional e social incluindo desde a higiene pessoal até a salubridade de forma mais ampla ${ }^{(16)}$. Por outro lado, é interessante observar que mesmo com a idade avançada F1 continuava assumindo a responsabilidade pelos cuidados básicos de $\mathrm{M} 1$, o que evidencia a preservação de elementos importantes da definição de cuidado como: compromisso, ajuda e preservação da integridade, dignidade e singularidade ${ }^{(17)}$.

Entretanto, apesar de todas as ações desenvolvidas por sua família, ao longo da evolução do alcoolismo, M1 não se sentiu cuidada. Possivelmente, as experiências vivenciadas ao longo de trinta e quatro anos de dependência fizeram com que as demonstrações de carinho e afeto, consideradas pela família como cuidado, perdessem esse significado para M1. Isso confirma os resultados de outros estudos que evidenciaram o poder disruptivo do alcoolismo sobre os laços afetivos familiares, a dificuldade de aproximação e manutenção de confiança e de compartiIhamento de experiências entre a pessoa alcoolista e os demais membros de sua família e, também, os sentimentos ambivalentes que, muitas vezes, geram comportamentos agressivos no contexto doméstico ${ }^{(6,10,15)}$.

Um aspecto relevante para a enfermagem apontado por M1 é que as práticas desenvolvidas por sua mãe e sua 
filha tinham como foco o alcoolismo e não a sua pessoa. Para ela o cuidado está relacionado com as demonstrações de afeto, zelo, solidariedade, paciência e preocupação para com as pessoas. M1 não consegue perceber as ações desenvolvidas pelos familiares, ao longo dos anos, como sendo práticas de cuidado, considera-as como desrespeitosas, punitivas, excludentes que contribuem somente para aumentar seus sentimentos de solidão.

Com base nessa compreensão, sente-se desqualificada pela família que, por seu lado, não entende as dificuldades e o transtorno da mulher, nem sua forma de vivenciar o sofrimento. Nesse contexto, as exigências de cuidado tornam-se um fardo para a família, confirmando que esta forma de entendimento está, na maioria das vezes, associada ao desconhecimento do processo de adoecer e das possibilidades de recuperação e reintegração social de pessoas que desenvolvem transtornos dessa natureza ${ }^{(18)}$.

No âmbito da família, a relação de cuidado exige responsabilidade, compromisso e, sem dúvida, se desenvolve tendo por base o afeto, carinho e amor, existindo uma complementação entre os seres humanos envolvidos no cuidado. Quando se evidencia essa complementação, o cuidar se torna uma relação significativa que se manifesta através da preocupação com o outro, impregnado de solicitude, traduzindo-se, então, como cuidado ${ }^{(17)}$. Entretanto, não se pode esquecer que a sobrecarga fica maior para quem cuida e, na medida em que os outros familiares acabam se afastando e pouco se relacionando com a pessoa doente, o cuidador passa a necessitar, também, de cuidados $^{(18)}$.

Considerando que o ser humano não vive sozinho e que a família é sua rede de suporte mais próxima ${ }^{(16)}$, compreende-se porque, apesar dos longos anos de dependên-

\section{REFERÊNCIAS}

1. Laranjeira R, organizador. I Levantamento Nacional sobre Padrões de Consumo de Álcool na População Brasileira. Brasília: Secretaria Nacional Antidrogas; 2007.

2. Brasil. Ministério da Saúde. Sistema de Informação em Saúde das Principais Instituições da Saúde no Rio Grande do Sul Brasil. Perfil da saúde do brasileiro. Porto Alegre; 2009.

3. Gehrke BNC. Considerações sobre o alcoolismo. Pelotas: EDUCAT; 2001.

4. César BAL. Alcoolismo feminino: um estudo de suas peculiaridades: resultados preliminares. J Bras Psiquiatr. 2006; 55(3): 208-11.

5. Nóbrega MPS, Oliveira EM. Mulheres usuárias de álcool: análise qualitativa. Rev Saúde Pública. 2005;39(5):816-23.

6. Silva MRS. Família de alcoolista: o retrato que emerge da literatura. Fam Saúde Desenvolv. 2003;5(1):9-18. cia, F1 não deixou de cuidar, como pode ser evidenciado em muitas passagens da história de vida desta família. Apesar do sofrimento ter mobilizado inúmeros sentimentos negativos em M1, ainda, assim, emergiram concomitantemente os desejos de ajudar a filha e resgatá-la da condição em que se encontrava.

\section{CONCLUSÃO}

Apesar de este estudo estar centrado nas práticas de cuidado desenvolvidas no âmbito da família, seus resultados constituem alertas importantes para a prática de enfermagem com pessoas alcoolista, especialmente com mulheres alcoolista. Primeiramente, apontam que apesar dos constantes conflitos e dos longos anos de convivência dolorosa, F1 sempre cuidou da filha alcoolista. Este é um ponto de partida significativo para o trabalho da enfermagem, pois cuidar de mulheres na condição de alcoolistas requer um planejamento que precisa levar em conta o desgaste do cuidador e não apenas a pessoa dependente.

Os resultados apontam, também, para a importância de identificar sinais precoces de abuso de bebida alcoólica, principalmente nos dias atuais em que esse comportamento é muito estimulado entre os jovens. Da mesma forma, alertam para o forte impacto do preconceito em relação ao alcoolismo feminino, sobre a saúde das mulheres e, principalmente sobre seu papel de mãe e de cuidadora da família. Particularmente, este estudo destaca o descompasso entre a percepção da pessoa cuidadora e a mulher alcoolista quando a capacidade de diálogo entre elas está comprometida pela própria doença.
7. Castells MA, Furlanetto LM. Validade do questionário CAGE para rastrear pacientes com dependência ao álcool internados em enfermarias clínicas. Rev Bras Psiquiatr. 2005; 27(1):54-57.

8. Andrade LHSG, Viana MC, Silveira CM. Epidemiologia dos transtornos psiquiátricos na mulher. Rev Psiquiatr Clin. 2006;33(2):43-54.

9. Galduróz JC, Caetano R. Epidemiologia do uso de álcool no Brasil. Rev Bras Psiquiatr. 2004;26 Supl 1:3-6.

10. Nóbrega MPS, Oliveira EM. Dando voz às mulheres usuárias de álcool. Acta Paul Enferm. 2003;16(3):71-80.

11. Minayo MCS. O desafio do conhecimento: pesquisa qualitativa em saúde. 10ạ ed. São Paulo: Hucitec; 2007.

12. Masur J. Etiologia do alcoolismo. In: D’Albuquerque LAC, Silva AO, organizadores. Doença hepática alcoólica. São Paulo: Savier; 1990. p. 9-13. 
13. Leininger MM. Culture care diversity and universality: a theory of nursing. New York: Wiley; 1991.

14. Filizola CLA, Perón CJ, Nascimento MMA. Compreendendo o alcoolismo na família. Esc Ana Nery Rev Enferm. 2006;10(4):660-70.

15. Rossato VMD, Kirchhof ALC. Famílias alcoolistas: a busca de nexos de manutenção, acomodação e repadronização de comportamentos alcoolistas. Rev Gaúcha Enferm. 2006; 27(2):251-7.
16. Elsen I. Cuidado familial: uma proposta inicial de sistematização. In: Elsen I, Marcon SS, Silva MRS, organizadoras. O viver em família e sua interface com a saúde e a doença. $2^{\text {a }}$ ed. Maringá: Eduem; 2004. p. 19-28.

17. Waldow VR. Atualização do cuidar. Chia. 2008;8(1):85-96.

18. Moreno V. Familiares de portadores de transtorno mental: vivenciando o cuidado em um Centro de Atenção Psicossocial. Rev Esc Enferm USP. 2009;43(3):566-72. 